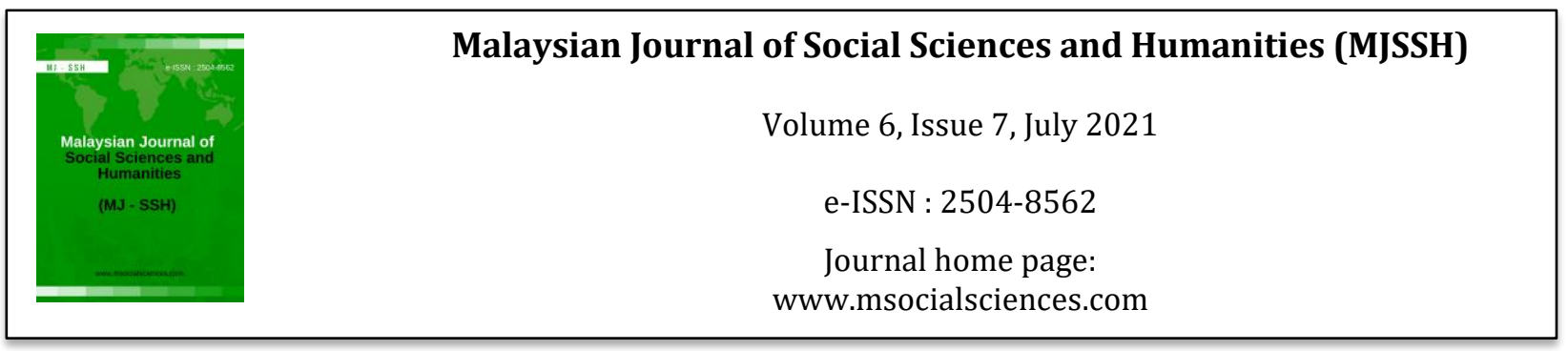

\title{
Peranan Modul ISRA dalam Membantu Kepulihan Bekas Klien di Kedah, Malaysia
}

\author{
Mohammad Adam Danial Hafiz Goh'1, Mohd Roslan Rosnon', Asnarulkhadi Abu Samah' \\ 1Jabatan Sains Kemasyarakatan dan Pembangunan, Fakulti Ekologi Manusia, Universiti Putra Malaysia (UPM)
}

Correspondence: Mohd Roslan Rosnon (roslan rosnon@upm.edu.my)

\begin{abstract}
Abstrak
Agensi Antidadah Kebangsaan telah melancarkan Modul Islamic Spiritual Rehabilitation Approach (ISRA) sebagai instrumen holistik bagi rawatan dan pemulihan bekas penagih dadah melalui kaedah mengubati masalah ketidakstabilan jiwa secara amalan kerohanian. Oleh itu, kajian ini bertujuan meneliti pandangan bekas klien dalam komuniti terhadap keberkesanan Modul ISRA dan mengenal pasti kefungsian sosial terhadap kepulihan bekas klien dalam komuniti. Kajian ini dilaksanakan secara kualitatif menggunakan pendekatan exploratory. Kajian ini menggunakan pensampelan bertujuan iaitu 16 orang informan telah terlibat terdiri daripada bekas klien ISRA yang compliant dan boleh terlibat diri dalam temu bual. Pengumpulan data dilakukan secara temu bual mendalam menggunakan pendekatan naturalistic inquiry atau constructionism bagi memperoleh data primer. Analisis tematik secara manual dilakukan terhadap data kajian bagi membentuk tema dalam menilai kesemua objektif kajian. Hasil kajian menunjukkan, bekas klien ISRA berpandangan, Modul ISRA dari segi kandungan, struktur, kaedah pengajaran dan pembelajaran adalah sangat baik dalam membantu kepulihan mereka. Kajian ini merumuskan, bekas klien memberikan pandangan positif terhadap keberkesanan Modul ISRA. Implikasi kajian ini mencadangkan, sebarang dasar atau pembinaan modul pemulihan perlu berfokus kepada keterlibatan persekitaran sosial klien bagi menyokong kepulihan klien secara berterusan setelah mereka keluar pusat.
\end{abstract}

Kata kunci: Modul ISRA, dadah, kerohanian, komuniti, kepulihan

\section{The Roles of ISRA Module in the Recovery of Former Clients in Kedah, Malaysia}

\begin{abstract}
The National Anti-Drugs Agency has launched the Module Islamic Spiritual Rehabilitation Approach (ISRA) as a holistic method for cure and rehabilitation for former drug addicts by providing help to stabilize the emotion via spiritual practices. Therefore, this study aimed to examine the views of former clients in the community on the effectiveness of ISRA Modul. This study was conducted qualitatively using an exploratory approach. This study used purposive sampling where 16 informants were involved consisting of former ISRA clients who are compliant and able to participate in the interview session. Data collection was done through in-depth interviews using naturalistic inquiry or constructionism approach. Manual thematic analysis was performed on the data to attain a theme in evaluating all the objectives of the study. As a result, ISRAs former clients opined that ISRA Module in terms of content, structure, teaching and learning methods was efficacious in helping their recovery. This study concludes that former clients gave a positive view on the effectiveness of ISRA Module. The implications of this
\end{abstract}


study suggest any policy or construction of rehabilitation modules should focus on the involvement of the client's social environment to support the client's ongoing recovery upon leaving the centre.

Keywords: ISRA Module, drug, spiritual, community, recovery

\section{Pengenalan}

Sehingga kini, kurangnya kajian empirikal dilaksanakan bagi menelusuri faktor-faktor kelangsungan kepulihan bekas penagih dadah yang telah keluar daripada pusat (bekas klien) yang mampu untuk kembali menjalani semula kehidupan sehari-hari mereka bersama komuniti. Sehubungan dengan itu, makalah ini memberi fokus perbincangan berkenaan peranan Modul ISRA dan kefungsian sosial terhadap kepulihan bekas klien dalam komuniti di Kedah, Malaysia. Perkara penting yang dibahaskan dalam makalah ini ialah mengenai apakah pandangan bekas klien dalam komuniti terhadap keberkesanan Modul ISRA dalam program rawatan dan pemulihan?.Umumnya, banyak sebab yang mendasari seseorang bekas penagih itu sama ada kembali menagih semula (relaps) atau mampu untuk kekal pulih setelah keluar pusat rawatan. Antaranya ialah faktor diri sendiri, keluarga, persekitaran, pegangan agama yang rendah, persekitaran dan kurang sokongan daripada majikan dan kerajaan (Fauziah, 2008; Fauziah et al., 2009; Fadzli \& Sabir, 2011; Mohammad Johdi, 2012; Wan Salmi, 2012; Fauziah et al., 2013; Suppiah et al., 2014; Sabir \& Fadzli, 2014; Mansor et al., 2017; Fauziah et al., 2017; Rozmi et al., 2017; Adibah \& Rozmi, 2018; Mohd Alif et al., 2018; Abdul Munir, Abd Rahman \& Mohd Noor, 2018; Nazira et al., 2019; Ezarina, Fauziah \& Nazirah, 2020; Amran, Fuziah \& Saralah, 2020).

Di Malaysia, Agensi Antidadah Kebangsaan (AADK) menerajui usaha melaksanakan program rawatan dan pemulihan kepada penagih-penagih dadah. Melalui institusi di bawah AADK seperti Pusat Pemulihan Jagaan dan Rawatan (CCRC), beberapa modul pemulihan dirangka dan dilaksanakan antaranya termasuklah modul psikososial, modul terapeutik komuniti, latihan kemahiran dan modul psikospiritual. Selain itu, program pemulihan dalam komuniti juga penting dalam mencegah penagihan relapse antaranya seperti aktiviti kaunseling serta penempatan dalam pekerjaan dan latihan kemahiran. Wujud juga teknik biofeedback sebagai alternatif pemulihan bekas penagih yang dibangunkan sebagai terapi untuk mengawal tingkah laku serta fungsi badan manusia melalui proses psikologi dan fisiologi (Simona, 2010). Dalam membincangkan modul psikospiritual, Menurut Mahmood Nazar (2006), pendekatan kerohanian iaitu pembangunan spiritual atau penglibatan agama dan tradisional merupakan kaedah rawatan yang semakin popular. Mohd Hefzan dan Muhammad Nubli (2019) turut menjelaskan, individu yang mempunyai pegangan agama yang kuat, ternyata kurang terlibat dengan dadah dan seandainya golongan ini terlibat dengan penyalahgunaan dadah sekalipun, maka pemulihan berbentuk spiritual adalah sesuai (Galanter et al., 2006; Mohd Hefzan \& Muhammad Nubli, 2019). AADK sedar dan tiba masanya untuk melihat aspek kerohanian/spiritual sebagai instrumen rawatan dan pemulihan.

Lantaran itu, AADK telah bertindak membangunkan modul komprehensif berasaskan pendekatan psikospiritual sebagai langkah baharu dalam program rawatan dan pemulihan di institusi-institusi pemulihan dadah kendaliannya di Malaysia. Modul Islamic Spiritual Rehabilitation Approach (ISRA) atau Pendekatan Pemulihan Kerohanian Islam merupakan modul yang holistik yang menggabungkan adaptasi modul Inabah dan modul sokongan psikososial (Agensi Antidadah Kebangsaan, 2017). Dengan kata lain, Modul ISRA ini selain mengekalkan program rutin berbentuk psikososial, ia turut dilengkapi dengan program psikospiritual sebagai landasan utama pemulihan. Hal inilah menjadi sandaran kepada makalah ini untuk memilih Modul ISRA untuk dinilai akan pandangan bekas klien berhubung keberkesanannya terhadap kepulihan mereka. Oleh itu, kajian ini cuba merungkai dan memahami pandangan bekas klien terhadap keberkesanan Modul ISRA dalam membantu bekas klien kekal pulih dalam komuniti. 


\section{Sorotan Literatur}

Dasar Dadah Negara 2017 (DDN 2017) telah dibentangkan dalam Mesyuarat Jemaah Menteri (MJM) dan diluluskan pada 10 Mac 2017 (Agensi Antidadah Kebangsaan, 2019). DDN 2017 ialah penambahbaikan yang dilaksanakan kepada Dasar Dadah Negara (DDN) pertama yang telah digubal pada tahun 1996. Kerajaan berpendapat bahawa Dasar Dadah Negara (DDN) 1996 perlu dikemas kini agar lebih menyeluruh dengan tindakan yang lebih komprehensif dan selaras dengan perubahan semasa yang perlu dilaksanakan dalam menangani isu berkaitan dadah (Agensi Antidadah Kebangsaan, 2019). Keperluan ini telah diambil tindakan oleh AADK, bermula dengan proses semakan Dasar Dadah Negara sejak tahun 2014 yang melibatkan pelbagai pihak berkepentingan dan pihak swasta yang berkaitan untuk memberikan input dan pandangan bagi penambahbaikan kepada DDN ini. Matlamat DDN 2017 telah ditambah baik bagi mewujudkan negara dan masyarakat Malaysia yang bebas daripada ancaman dadah untuk menjamin kesejahteraan hidup bermasyarakat, mengekalkan kestabilan dan ketahanan nasional (Agensi Antidadah Kebangsaan, 2019). DDN mengutamakan pendekatan dan strategi secara kolaboratif dan melibatkan pelbagai pihak pelaksana melalui pelaksanaan lima (5) teras utama iaitu: (i) pencegahan; (ii) rawatan dan pemulihan; (iii) penguatkuasaan; (iv) pengurangan kemudaratan; dan (v) kerjasama antarabangsa (Agensi Antidadah Kebangsaan, 2019).

AADK merupakan agensi utama yang bertanggungjawab menjalankan program rawatan dan pemulihan kepada penagih-penagih dadah di negara ini. Tanggungjawab merawat dan memulihkan penagihpenagih dadah adalah selari dengan peruntukan Akta Penagih Dadah (Rawatan dan Pemulihan) 1983 berasaskan kepada falsafah bahawa penagih-penagih dadah merupakan pesakit yang memerlukan rawatan dan pemulihan. Pada masa ini, AADK melaksanakan dua kaedah rawatan dan pemulihan iaitu: (i) pemulihan dalam institusi dan (ii) pemulihan dalam komuniti. Pelbagai institusi diwujudkan untuk tujuan pemulihan antaranya pemulihan dalam institusi (Klinik Cure \& Care dan Cure \& Care Rehabilation Centre (CCRC)); pemulihan dalam komuniti (Cure \& Care Service Centre (CCSC) dan Caring Community House $(\mathrm{CCH})$ ); program kerjaya dan latihan vokasional (Cure \& Care Vocasional Centre (CCVC)); pencegahan - pendidikan dan kesedaran awam (SHIELDS, TEKAD, SMART), Skuad AADK dan Pengesanan dan Pengawasan.

Di Malaysia, pemulihan dalam institusi meliputi beberapa modul seperti modul psikososial, modul terapeutik komuniti, modul latihan kemahiran, modul kerohanian dan sebagainya. Modul Psikososial merujuk kepada program pemulihan yang dijalankan berdasarkan Modul Cure and Care yang berteraskan kepada perkembangan psikologi seseorang dalam mengekalkan kepulihan (Agensi Antidadah Kebangsaan, 2017). Modul terapeutik komuniti pula merujuk kepada pendekatan pemulihan dengan menekankan konsep nilai kekeluargaan, suri tauladan, rangsangan rakan sebaya, kemahiran pengendalian diri dalam usaha mencapai kepulihan diri (Nurfatin Afza, Nobaya \& Hanina Halimatusaadiah, 2016). Manakala modul latihan kemahiran pula, ia menawarkan latihan vokasional serta penempatan pekerjaan kepada OKP.

Pemulihan dalam komuniti pula seperti kaunseling individu, kelompok dan keluarga; penempatan dalam pekerjaan/latihan; kemahiran mencegah penagihan semula dan sebagainya. Selain itu, ada juga yang menggunakan teknik biofeedback. Teknik biofeedback merupakan satu teknologi yang berkembang pesat dalam menilai dan memproses pemulihan individu melalui pelbagai situasi seperti masalah jiwa, tekanan perasaan dan keresahan (Peper et al. 2008). Selain itu, biofeedback merujuk kepada teknik yang dibangunkan bagi menghubungkan proses psikologi dan fisiologi yang berlaku dalam tubuh manusia tanpa disedari. Teknik ini merupakan satu teknik terapi untuk mengawal tingkah laku serta fungsi badan manusia (Simona, 2010).

Sejak belakangan ini, modul kerohanian merupakan kaedah yang semakin popular (Mahmood Nazar, 2006). Modul ini atau dikenali sebagai psikospiritual menggunakan rawatan berteraskan ajaran Islam seperti yang digariskan al-Quran dan Sunah sebagai kaedah memulihkan bekas penagih dadah (Mohd Hefzan \& Muhammad Nubli, 2019). Modul berbentuk spiritual ini penting sepertimana fizikal tubuh manusia yang memerlukan nutrisi dan zat makanan untuk sihat dan cergas, kerohanian juga penting sebagai makanan spiritual dalam menghalang daripada melakukan perkara yang negatif. Rawatan menggunakan pendekatan kerohanian mampu memulihkan masalah ketagihan dadah serta mengekalkan 
kepulihan klien dengan melihat kepada perubahan sikap dan sifat klien semasa dalam pusat (Agensi Antidadah Kebangsaan, 2017).

\section{Modul ISRA}

AADK telah membangunkan modul berasaskan pendekatan psikospiritual sebagai salah satu pendekatan utama dalam program rawatan dan pemulihan di institusi-institusi pemulihan dadah di bawah kendaliannya. Pendekatan pemulihan kerohanian Islam (Modul ISRA) ialah satu pendekatan yang dibangunkan berasaskan kepada input-input spiritual dan adaptasi Model Inabah yang menggabungkan ciri-ciri ketuhanan dan pembangunan secara holistik dalam usaha merawat dan memulihkan penagihpenagih dadah (Agensi Antidadah Kebangsaan, 2017). Modul ISRA boleh diklasifikasikan sebagai satu pendekatan rawatan dan pemulihan penagih dadah yang memberi fokus kepada pembersihan jiwa dan kendiri yang berteraskan kepada elemen-elemen ketuhanan dan amalan spiritual Islam bersumberkan alQuran, al-Sunnah dan amalan para ulama' salafus soleh yang tidak bercanggah dengan prinsip-prinsip syariah (Agensi Antidadah Kebangsaan, 2017). Pendekatan Modul ISRA dimantapkan lagi dengan pelbagai program dan aktiviti rawatan dan pemulihan sokongan dengan menggunakan modul psikososial. Gabungan kedua-dua pendekatan ini diyakini akan menghasilkan impak kepulihan yang lebih holistik (Agensi Antidadah Kebangsaan, 2017).

Dua komponen utama dalam pendekatan ini ialah modul teras psikospiritual (disesuaikan daripada Model Inabah) dan modul sokongan psikososial (Agensi Antidadah Kebangsaan, 2017). Pendekatan ini berteraskan kepada konsep 'pengembalian' atau 'pemulihan' yang bermaksud proses kembalinya seseorang dari jalan yang menjauhi Allah ke jalan yang mendekati Allah (Agensi Antidadah Kebangsaan, 2017). Terdapat tiga (3) asas utama yang diterapkan dalam pendekatan ini, yang dijadikan sebagai input program dan aktiviti rawatan dan pemulihan dadah iaitu i) taubat (kembali kepada Allah), ii) benteng keimanan dan iii) perisai ketakwaan (Agensi Antidadah Kebangsaan, 2017). Kaedah rawatan Terapi Psikospiritual Islam merupakan satu kaedah yang unik dan lebih menekankan kepada pembentukan rohani seseorang dalam membantu mereka untuk pulih. Kaedah ini juga menggunakan unsur dan pendekatan tertentu dalam melakukan rawatan seperti memberi penekanan terhadap sesuatu amalan sebagai amalan utama untuk membantu klien kekal pulih (Agensi Antidadah Kebangsaan, 2017).

Terdapat tiga (3) Modul utama ISRA, iaitu pertama, Modul Orientasi iaitu modul pengendalian awal dan pengenalan kepada program; kedua, Modul Psikospiritual iaitu modul teras (merangkumi 8 komponen utama iaitu, Talqin, Terapi Mandi, Terapi Solat, Terapi Zikir Kalimah Toyyibah, Khotaman (Himpunan Doa-Doa), Manaqiban (Kisah Riwayat), Tadarus Al-Quran dan Terapi Puasa); dan ketiga, Modul Psikososial iaitu modul sokongan kepada modul teras (Agensi Antidadah Kebangsaan, 2017). Matlamat utama pendekatan ini adalah untuk mengubati masalah ketidakstabilan jiwa dan diri seseorang yang merupakan akar kepada masalah. Melalui program ini, klien diberi kefahaman tentang amalan-amalan kerohanian yang boleh menyucikan jiwa, mengubah tingkah laku dan dalaman klien, menggalakkan klien melakukan ibadah harian yang boleh mendekatkan diri dengan Allah SWT secara istiqamah agar kekal dalam kepulihan (Agensi Antidadah Kebangsaan, 2017).

Berdasarkan lapan (8) komponen utama modul ISRA ini, banyak memberi fokus kepada amalan-amalan agama dan kerohanian. Input-input psikospiritual seperti amalan berdoa (Ariyanto, 2006; Longshore, Anglin \& Conner, 2009) dan solat (Fatimah, 2008) telah dibuktikan berkesan memberi impak positif dalam pemulihan penagih dadah. Nas al-Quran sendiri telah menjelaskan bahawa manusia dicipta dalam keadaan keluh kesah, dan akibat keluh kesah itulah banyak berlakunya perlakuan salah dan tidak bermoral termasuklah penagihan dadah (Yuseri, Sapora \& Marina Munira, 2007). Said (1999) merumuskan bahawa sifat keluh kesah ini tidak dapat diatasi oleh manusia melainkan manusia itu mengamalkan solat, infaq, membenarkan hari akhirat, rasa gerun dengan azab Allah, memelihara kemaluan, dan memberikan kesaksian dengan penuh kebenaran dan keadilan. Menurut Fauziah et al. (2017) mendapati bahawa program spiritual dan agama dapat membantu memberi kekuatan kepada penagih untuk mengubah tingkah lakunya meninggalkan dadah. Oleh itu, pelaksanaan modul berasaskan psikospiritual hendaklah diperkasakan lagi sebagai satu daya usaha untuk menurunkan kadar relaps dalam kalangan OKP. 


\section{Metod Kajian}

Kajian ini dilaksanakan secara kualitatif. Pendekatan kualitatif adalah untuk mengenal pasti proses tertentu dalam mengetahui dan memahami sesuatu perkara yang berlaku (Willig, 2013). Reka bentuk penyelidikan yang digunakan dalam kajian ini adalah Kajian exploratory. Reka bentuk penyelidikan ini juga boleh di buat ke atas perkara yang biasa, tetapi jarang dikaji. Exploratory merupakan reka bentuk kajian untuk menginterpretasikan fenomena dalam terma makna yang disampaikan oleh orang lain kepada penyelidik (Denzin \& Lincoln, 2011).

Lokasi kajian dijalankan di Kedah. Pemilihan lokasi kajian adalah atas nasihat daripada AADK berdasarkan kepada saiz populasi yang besar di negeri tersebut. Kebanyakan bekas klien ISRA tinggal di Kedah. Seperti diketahui, Pusat Pemulihan Jagaan dan Rawatan (CCRC) pertama yang menjalankan Modul ISRA adalah di CCRC Sungai Ruan, Raub pada 2015, kedua di CCRC Perlop, Perak dan ketiga di CCRC Tiang dua, Melaka.

CCRC Sungai Ruan memiliki bekas klien yang paling ramai dan berada dalam komuniti. Kebanyakan klien yang mengikuti Modul ISRA di Sungai Ruan merupakan klien yang menetap di utara tanah air. Oleh itu, berdasarkan data yang diberikan oleh pihak AADK, populasi bekas klien ISRA majoritinya berasal dan menetap di Kedah. Dalam kajian ini populasi kajian ialah mereka yang merupakan bekas klien Modul ISRA.

Berdasarkan statistik yang diberikan oleh AADK pada tahun 2018, seramai 457 klien telah mengikuti Modul ISRA di tiga buah CCRC. Bilangan informan bagi kajian ini adalah berasaskan kepada objektif kajian, kesesuaian masa dan kesahan serta kebolehpercayaan kajian untuk dicapai. Bilangan informan kajian adalah bergantung kepada titik tepu dapatan kajian. Titik tepu ini dianggap tercapai apabila tambahan responden atau informan tidak lagi menghasilkan pengetahuan baharu (tepu). Seramai 16 orang informan yang terlibat dalam kajian ini yang dipilih secara pensampelan bertujuan. Lokasi tidak mewakili bilangan yang setara berikutan kajian ini mengguna pakai teknik pensampelan bertujuan. Pensampelan bertujuan dipilih kerana ia dapat menentukan responden yang sesuai dengan tujuan kajian. Maklumat penetapan kriteria informan kajian ialah seperti berikut:

i. Bekas klien yang pernah mengikuti Modul ISRA.

ii. Mereka yang compliant

iii. Boleh melibatkan diri lebih daripada sekali temu bual.

Ketiga-tiga kriteria ini sangat penting dalam memastikan objektif kajian yang digariskan dapat dipenuhi. Teknik pengumpulan data menggunakan kaedah temu bual mendalam sebagai strategi untuk memperoleh dan mengumpulkan data primer. Analisis berasaskan tema secara manual dilakukan terhadap data kajian bagi membentuk tema dalam menilai kesemua objektif kajian ini. Tema dilakukan berdasarkan kepada transcribing temu bual. Tema diwujudkan berdasarkan analisis data kajian yang dilakukan melalui proses memeriksa, mengkategorikan, menjadualkan atau kombinasi beberapa penyataan bagi menunjukkan keseluruhan dapatan kajian (Newman, Thompson, \& Roberts (2006). Tema juga berdasarkan maklumat yang dominan yang diberikan oleh informan kajian.

\section{Hasil Kajian dan Perbincangan Kajian}

\section{Demografi Informan Kajian}

Informan kajian yang terlibat dalam kajian ini merupakan mereka yang tinggal di Kedah yang terdiri daripada pelbagai daerah dan mereka merupakan bekas klien ISRA. Kesemua informan yang terlibat dalam kajian ini adalah lelaki, berbangsa Melayu dan status pekerjaan mereka adalah bekerja. Majoriti informan kajian adalah mereka yang berumur bawah 30 tahun. Dari segi status perkahwinan pula, 3 orang informan ialah bujang, 6 orang didapati sudah berkahwin manakala 6 informan bercerai atau berpisah. Terdapat seorang informan berstatus kematian pasangan. Manakala dari segi pendidikan pula, 3 orang informan tidak bersekolah, 2 orang informan bersekolah rendah iaitu tahap pendidikan UPSR 
DOI: https://doi.org/10.47405/mjssh.v6i7.917

dan 8 orang informan mempunyai pendidikan sehingga sekolah menengah rendah iaitu PMR. Seramai 3 orang informan mendapat pendidikan sehingga SPM. Oleh itu, majoriti informan dalam kajian ini mendapat pendidikan sehingga PMR. Dari segi pekerjaan pula, kesemua informan mempunyai pekerjaan. Antara pekerjaan informan ialah petani, ladang dan kerja kampung iaitu 10 orang informan, pekerja buruh iaitu 3 orang informan, pekerja swasta iaitu 2 orang informan dan bekerja sendiri iaitu seorang informan. Informan yang bekerja sendiri ini, beliau membuka perniagaan kedai runcit di kawasan penempatannya. Dari segi pendapatan pula, seramai 6 orang informan memiliki pendapatan kurang daripada RM600.00 sebulan, 6 orang informan pula memiliki pendapatan sebanyak RM601.00 hingga RM1200.00 sebulan dan 4 orang informan memiliki pendapatan RM1201.00 ke atas sebulan. Dapatan kajian menunjukkan bahawa informan yang memiliki pendapatan lebih RM1200 sebulan adalah mereka yang bekerja sendiri dan pekerja swasta. Hal ini jelas menunjukkan bahawa majoriti informan kajian berada di bawah garis kemiskinan iaitu RM1200.00 ke bawah (Unit Perancang Ekonomi, 2020). Jadual 1 menunjukkan latar belakang bekas klien yang terlibat dengan kajian ini.

Jadual 1: Maklumat latar belakang bekas klien

\begin{tabular}{|c|c|}
\hline Pemboleh Ubah & n $(\%)$ \\
\hline \multicolumn{2}{|l|}{ Umur } \\
\hline 30 tahun ke bawah & $8(50 \%)$ \\
\hline 31 tahun -40 tahun & $4(25 \%)$ \\
\hline 41 tahun ke atas & $4(25 \%)$ \\
\hline \multicolumn{2}{|l|}{ Jantina } \\
\hline Lelaki & $16(100 \%)$ \\
\hline \multicolumn{2}{|l|}{ Kaum } \\
\hline Melayu & $16(100 \%)$ \\
\hline \multicolumn{2}{|l|}{ Status Perkahwinan } \\
\hline Bujang & $3(18.8 \%)$ \\
\hline Berkahwin & $6(37.5 \%)$ \\
\hline Bercerai atau Berpisah & $6(37.5 \%)$ \\
\hline Kematian Pasangan & $1(6.2 \%)$ \\
\hline \multicolumn{2}{|l|}{ Tahap Pendidikan } \\
\hline Tidak Bersekolah & $3(18.8 \%)$ \\
\hline UPSR & $2(12.4 \%)$ \\
\hline PMR & $8(50 \%)$ \\
\hline SPM & $3(18.8 \%)$ \\
\hline \multicolumn{2}{|l|}{ Status Pekerjaan } \\
\hline Bekerja & $16(100 \%)$ \\
\hline \multicolumn{2}{|l|}{ Jenis Pekerjaan } \\
\hline Petani, Ladang atau Kerja Kampong & $10(62.5 \%)$ \\
\hline Pekerja Buruh & $3(18.8 \%)$ \\
\hline Pekerja Swasta & $2(12.5 \%)$ \\
\hline Bekerja Sendiri & $1(6.2 \%)$ \\
\hline \multicolumn{2}{|l|}{ Jumlah Pendapatan } \\
\hline$<$ RM600.00 & $6(37.5 \%)$ \\
\hline RM601.00 - RM1200.00 & $6(37.5 \%)$ \\
\hline >RM1201.00 & $4(25 \%)$ \\
\hline
\end{tabular}


DOI: https://doi.org/10.47405/mjssh.v6i7.917

\section{Pandangan Terhadap Modul Kepulihan}

Dua modul kepulihan yang dijalani oleh bekas klien ISRA iaitu modul psikososial dan modul psikospritual. Bahagian ini memberi fokus kepada pandangan bekas klien dalam komuniti terhadap keberkesanan modul ISRA yang mereka pernah ikuti. Adakah modul ini berjaya dan menyebabkan kepulihan klien? Informan kajian juga ditanyakan mengenai pandangan mereka tentang cara pelaksanaan atau pengendalian modul ini. Berikut merupakan pandangan informan terhadap modul kepulihan berdasarkan temu bual yang dijalankan.

\section{Modul Psikososial}

Modul Psikososial memberikan kebebasan pergerakan kepada klien di dalam pusat dengan memberi fokus kepada pemulihan fizikal dan psikologikal di samping penerapan konsep tough and rugged. Modul ini juga membentuk disiplin dan fizikal klien melalui pemakanan, latihan kawat dan aktiviti-aktiviti fizikal lain. Berdasarkan temu bual dijalankan bersama informan, majoriti informan bersetuju bahawa modul psikososial membantu kepulihan klien. Majoriti informan juga mengatakan modul ini membantu kehidupan klien setelah keluar dari pusat. Modul psikososial dilihat sangat baik dan ilmunya berguna untuk menguruskan kehidupan setelah keluar dari pusat. Berikut merupakan kata-kata informan mengenai hal ini:
"Modul psikososial ini bagus memang membantu kepulihan saya... banyak manfaat modul ini dan boleh dipraktikkan sekarang" (Informan 3)
"Modul psikososial ya bantu dan banyak mengajar saya... boleh guna ilmu sekarang...” (Informan 7)
"Memang modul psikososial bagus...bantu kepulihan saya..." (Informan 13).

Majoriti informan juga menyatakan dengan mempelajari modul psikososial ini ia dapat membentuk disiplin mereka. Kawat ketika setiap pagi yang dilakukan berjaya membina disiplin mereka. Selain itu modul ini juga memupuk semangat patriotik melalui pembacaan rukun negara setiap pagi dan juga menyanyikan lagu Negaraku. Melalui modul ini juga, majoriti informan mengatakan mereka dapat mempelajari gaya hidup sihat melalui senaman yang dijalankan setiap pagi. Berikut merupakan katakata informan mengenai hal ini:
"Saya belajar tentang penjagaan diri... sebab pagi-pagi bersenam jadi badan pun sihat" (Informan 2)
"Setiap pagi menyanyi lagu Negaraku... jadi naikkan juga semangat patriotik... nyanyi lagu dan baca ikrar Rukun Negara, selain itu disiplin kan kita juga..." (Informan 10)
"Pagi berkawat dapatlah ajar kita berdisiplin... untuk kesihatan dengan bersenam...." (Informan 15)

Berdasarkan kata-kata informan jelas menunjukkan bahawa modul psikososial membantu dari segi kepulihan klien melalui pembentukan karakter mereka. Pembentukan karakter ini penting bagi membetulkan semula sikap dan tingkah laku mereka supaya memiliki nilai-nilai yang positif yang diterjemahkan melalui pemikiran dan tindakan mereka. Dari segi pengajaran pula, rata-rata informan bersetuju sesi pengendalian modul adalah baik dan sesuai dengan keperluan mereka. Berikut merupakan kata-kata informan mengenai hal ini:

$$
\begin{aligned}
& \text { "Jadual disusun rapi... sesuai dengan keperluan saya...” (Informan 4) } \\
& \text { "Pengendalian slot ok... seronok juga..." (Informan 7) }
\end{aligned}
$$


"Coach bagus... tidak ada masalah dengan mereka... kursus pun bagus ikut jadual..." (Informan 8)

Oleh hal yang demikian, berdasarkan kata-kata informan jelas menunjukkan bahawa pengendalian modul dijalankan dengan baik mengikut jadual yang telah ditetapkan. Informan juga menyatakan modul ini sesuai dengan keperluan mereka.

\section{Modul Psikospiritual (Modul ISRA)}

Terdapat tiga (3) sub-modul yang utama dalam Modul ISRA iaitu pertama, modul orientasi iaitu modul pengendalian awal dan pengenalan kepada program; kedua, modul psikospiritual atau Modul ISRA iaitu modul teras (8 komponen utama iaitu, Talqin, Terapi Mandi, Terapi Solat, Terapi Zikir Kalimah Toyyibah, Khotaman, Manaqiban, Tadarus Al-Quran dan Terapi Puasa); dan ketiga, modul psikososial iaitu modul sokongan kepada modul teras (Agensi Antidadah Kebangsaan, 2017). Matlamat utama Modul ISRA ini adalah untuk mengubati masalah ketidakstabilan jiwa dan diri seseorang yang merupakan akar kepada masalah. Melalui program ini, klien diberi kefahaman tentang amalan-amalan kerohanian yang boleh menyucikan jiwa, mengubah tingkah laku dan dalaman diri klien, menggalakkan klien melakukan ibadah harian yang boleh mendekatkan diri dengan Allah SWT secara istiqamah agar kekal dalam kepulihan (Agensi Antidadah Kebangsaan, 2017).

Berdasarkan temu bual yang dijalankan bersama informan kajian, majoriti informan bersetuju bahawa Modul ISRA membantu kepulihan klien. Modul ISRA dilihat sangat baik dan berguna untuk klien. Berikut merupakan kata-kata informan mengenai hal ini:

"Modul ISRA ini bagus sangat lain dengan modul-modul biasa. Memang membantu kepulihan saya..." (Informan 5)

"Saya beruntung diterima mempelajari Modul ISRA sebab banyak beri panduan kepada saya dan bagus untuk kepulihan saya...” (Informan 8)

“Memang Modul ISRA bagus... sangat membantu kepulihan saya...”(Informan 9).

Majoriti informan juga menyatakan Modul ISRA ini dapat memberikan ketenangan jiwa pada mereka. Melalui zikir-zikir yang dipelajari ia dapat mengisi jiwa mereka. Selain itu, majoriti informan juga menyatakan bahawa Modul ISRA ini dapat memantapkan amalan-amalan kerohanian mereka. Mereka dapat mempelajari ilmu agama dengan lebih baik dan mendalam serta menjadi petunjuk kepada kehidupan seharian mereka. Oleh itu, Modul ISRA ini boleh menjadi benteng kepada mereka untuk terjebak semula dengan najis dadah ini. Berikut merupakan kata-kata informan mengenai hal ini:

"Saya dulu bukan tahu sangat agama. Modul ISRA ini bagus saya belajar banyak tentang agama... jiwa rasa tenang..." (Informan 1)

"Modul ISRA ini buat jiwa rasa tenang... zikir hari-hari... jiwa yang kosong pun terisi... sangat bagus diamalkan...." (Informan 4)

"Kekadang amalan kita ada yang tidak betul... Modul ISRA bagus saya belajar bagaimana nak sebut syahadah dengan betul... sangat terkesan dekat hati..." (Informan 6)

Berdasarkan kata-kata informan jelas menunjukkan bahawa modul ISRA ini membantu kepulihan klien melalui pembentukan kerohanian dan jiwa mereka. Modul ini dapat memberi ketenangan kepada mereka dan memberi peluang kepada mereka untuk mempelajari serta mendekatkan diri dengan agama. Pembentukan secara dalaman pada diri ini penting bagi mengisi ruang-ruang kosong yang ada dalam hidup mereka dan menjadi benteng daripada melakukan kesilapan dan kesalahan semula. Informan 
kajian juga ditanya mengenai kefahaman mereka mengenai Modul ISRA ini dari segi tujuan modul ini dilaksanakan. Berikut merupakan kata-kata informan mengenai hal ini:

"Contoh solat sunat... bagus tujuannya untuk menghapus dosa-dosa kita yang lama... jadi jika kita selalu solat kita boleh banyak meminta ampun... selain itu disiplinkan kita juga...” (Informan 14)

"Puasa untuk tahan kita dari melakukan kesalahan... dengan puasa kita akan rasa sabar... dan juga dapat merasakan keperitan hidup orang lain yang susah..." (Informan 12)

"Zikir ini menyucikan jiwa... dengan membasahi lidah dengan zikir jiwa akan tenang...” (Informan 11)

Berdasarkan jawapan informan di atas, ia menunjukkan bahawa mereka faham akan Modul ISRA dengan sangat jelas. Walaupun mereka sudah keluar dari pusat, namun mereka masih mengingati tujuan dan objektif setiap program dalam Modul ISRA ini. Kefahaman ini sangat penting kerana setiap tindakan atau perbuatan itu perlu ada sebab-sebab ia dilakukan. Dengan kefahaman ini ia akan mendatangkan perasaan yang ikhlas untuk melakukannya. Mereka juga masih mengamalkannya di luar pusat walaupun tidak semua perkara. Berikut merupakan kata-kata informan mengenai hal ini:

"Kekadang saya lakukan... kekadang tidak... tapi solat saya jaga...” (Informan 16)

"Saya kekadang buat... macam puasa kekadang tak buat sebab bekerja... tapi Ramadan puasa la...." (Informan 1)

"Zikir saya buat juga... tapi ada juga yang tak buat macam mandi 40 gayung... tapi kebanyakan masih buat" (Informan 3)

Berdasarkan kata-kata informan majoritinya tidak mengamalkan semua amalan yang dipelajari ketika dalam pusat. Namun ada juga beberapa amalan wajib dan sunat yang mereka lakukan mengikut kesesuaian masa dan keperluan mereka. Namun, berdasarkan temu bual yang dijalankan tiada seorang pun yang tidak mengamalkan langsung amalan-amalan yang dipelajari ketika di dalam pusat. Informan juga ditanya apakah kekangan yang menghalang mereka untuk melaksanakan kesemua amalan tersebut. Antara jawapan yang diberikan, majoriti mengatakan isu masa yang terlalu padat, keadaan kerja yang tidak mengizinkan dan masalah kesihatan mereka. Berikut merupakan kata-kata informan mengenai hal ini:

"Tak semua saya buat sebab kerja jadi tak cukup masa... yang wajib saya lakukan" (Informan 4)

"Masalah kesihatan menghalang untuk berpuasa... solat tidak tinggal... puasa Ramadan saya buat, cuma sunat susah sikit" (Informan 7)

"Kita kerja shif... kekadang susah nak lakukan solat sunat malam... tapi yang wajib kita buat..." (Informan 8)

Berdasarkan jawapan informan di atas, ia menunjukkan bahawa amalan-amalan wajib tidak ditinggalkan informan. Namun, amalan sunat ada yang masih diteruskan dan ia bergantung kepada keadaan informan. Informan juga ditanya mengenai sama ada mereka menjadi orang yang berbeza setelah melalui Modul ISRA ini. Berikut merupakan jawapan informan mengenai hal ini:

"Dulu saya tidak jaga solat... sekarang saya jaga... banyak perubahan diri saya setelah mengikuti Modul ISRA (Informan 14) 
"Solat sunat saya banyak belajar... dulu tak tahu pun solat sunat... sekarang dah tahu" (Informan 13)

"Dulu kalau puasa pun payah... sekarang puasa dah boleh..." (Informan 12)

Berdasarkan jawapan informan, jelas menunjukkan adanya perubahan dalam tingkah laku mereka terhadap amalan agama. Majoriti informan merasakan adanya perubahan dari segi pengetahuan dan amalan terhadap agama. Ini merupakan satu kesan yang baik terhadap bekas klien apabila modul ini berjaya meningkatkan amalan kerohanian bekas klien. Amalan ini penting bagi penyucian jiwa sepertimana objektif Modul ISRA ini. Informan juga ditanya dari segi pengendalian program semasa di dalam pusat. Majoriti informan mengatakan program ISRA yang diikuti teratur mengikut keperluan fasa/peringkat. Majoriti informan juga menyatakan tempoh program Modul ISRA yang dijalankan adalah sesuai dan kaedah yang dijalankan dalam program ISRA juga sesuai. Berikut merupakan katakata informan mengenai hal ini: (Informan 5)

"Program dilaksanakan dengan baik... teratur dan sesuai ikut keperluan kami"

\author{
"Kaedah yang digunakan pun mudah faham... tempoh masa pun sesuai... sangat \\ sesuai dengan jiwa" (Informan 11) \\ "Tempoh masa sesuai... kaedah pun buat kita mudah faham lagi-lagi saya ni bukan \\ arif bab agama... ok la..." (Informan 10)
}

Berdasarkan jawapan informan jelas menunjukkan bahawa program ISRA dari segi pengendaliannya adalah baik dan tersusun sesuai dengan keperluan informan kajian. Dari segi kredibiliti guru yang mengajar modul ini, majoriti informan menyatakan tenaga pengajar/fasilitator mahir dengan apa yang diajar. Selain itu, informan juga menyatakan tenaga pengajar/fasilitator berjaya menarik minat mereka untuk mengikuti program ISRA sehingga menimbulkan kesedaran terhadap diri mereka. Berikut merupakan kata-kata informan mengenai hal ini:

"Ustaz bagus mengajar... mudah faham apa mereka ajar..." (Informan 2)

"Cikgu ajar saya faham.. mereka pakar... mereka ajar buat saya tertarik... kekadang kalau tidak tahu mereka akan jelaskan dengan baik..." (Informan 6)

"Ustaz ajar jelas... seronok dengan kuliah agama... kekadang bila ustaz ajar tu sampai dalam hati... wujudlah keinsafan...” (Informan 9)

Secara keseluruhan, dapatan kajian menggambarkan pandangan informan terhadap modul pemulihan yang pernah mereka ikuti ketika berada dalam pusat. Hampir kesemua informan memberikan maklum balas positif mengenai modul yang pernah mereka ikuti. Bagi Modul Psikospiritual iaitu Modul ISRA, walaupun ia masih baharu dan tidak semua agensi melaksanakannya, namun ia telah diterima dengan baik dan memberikan kesan positif kepada bekas klien ketika berada dalam komuniti. Hal ini juga menunjukkan bahawa klien penyalahgunaan dadah mula mempercayai keupayaan pendekatan psikospiritual dalam membantu mereka untuk pulih. Oleh itu, pengisian jiwa melalui penyucian jiwa dilihat memberikan kesan yang positif bagi merawat penagihan dadah.

\title{
Kesimpulan
}

Secara rumusannya, Modul ISRA diterima baik oleh bekas klien dalam membantu kepulihan bekas klien dalam komuniti. Sebagai sebuah negara yang membangun, Malaysia memerlukan modal insan yang berkualiti, berdaya saing dan mempunyai semangat juang yang tinggi bagi memelihara kesejahteraan negara. Oleh itu, dalam usaha memerangi masalah penagihan, pihak Kerajaan melalui Agensi Antidadah Kebangsaan dan seluruh masyarakat Malaysia haruslah bersama-sama berganding bahu memastikan 
hasrat Kerajaan untuk membasmi permasalahan penagihan relaps tercapai supaya negara mampu melahirkan generasi muda yang berpersonaliti unggul, lebih bermaruah dan mampu memimpin negara kelak. Modul Insan yang berkualiti kepada negara hanya akan lahir sekiranya masyarakat memainkan fungsi dan berperanan dalam mencapai matlamat pembangunan komuniti yang baik. Negara akan terus dibelenggu dengan masalah penyalahgunaan dadah dan ketandusan modal insan sekiranya kefungsian sosial tidak berlaku dalam kalangan komuniti. Sesungguhnya rawatan dan pemulihan penyalahgunaan dadah dalam kalangan penagih merupakan satu usaha yang tidak mudah kerana ia amat sukar untuk menemui kejayaan yang diinginkan ekoran terdapat pelbagai faktor yang saling bersangkutan dengannya. Seandainya kumpulan ini tidak dipulihkan, sudah pasti mereka akan terus meningkatkan permintaan terhadap dadah dan seterusnya menjejaskan proses rawatan dan pemulihan dadah yang diusahakan oleh pihak Kerajaan. Oleh itu, pemahaman latar belakang kehidupan, budaya dan psikologi penagih perlu dikaji kerana ia sebahagian daripada usaha membantu memulihkan dan membebaskan diri mereka daripada terus dibelenggu dengan najis dadah. Sudah tiba masanya juga Kerajaan melihat isu kepulihan penagihan dari sudut perubatan tetapi juga mengambil kira untuk menjadikan aspek spiritual sebagai komponen utama dalam rawatan dan pemulihan dalam institusi.

\section{Rujukan}

Abdul Munir, I., Abd Rahman, A. G. \& Mohd Noor, D. (2018).Wanita Dalam Gejala Tidak Bermoral Dan Kaedah Membina Kesejahteraan Hidup. Sains Humanika, 10(3-4), 155-163.

Adibah, H. \& Rozmi, I. (2018). Kebolehgajian Bekas Penagih Dadah Dari Perspektif Majikan. Jurnal Wacana Sarjana, 2(1), 1-14.

Agensi Anti Dadah Kebangsaan, (2017). Modul Pemulihan Penagih Dadah: Pendekatan Inabah. Putrajaya: Kementerian Dalam Negeri.

Agensi Anti Dadah Kebangsaan, (2019). Dasar Dadah Negara 2. Putrajaya: Kementerian Dalam Negeri.

Amran, I., Fuziah, S. \& Saralah, D. M. (2020). Faktor-Faktor Pencegahan Fenomena Relapse dalam Kalangan Penagih Dadah. Asian People Journal, 3(2). 161-168.

Ariyanto, M. (2006). Psikoterapi dengan doa. Suhuf, 18(1), 3-26.

Denzin, N. K., \& Lincoln, Y. S. (2011). The SAGE Handbook of Qualitative Research. Thousand Oaks, CA: Sage.

Ezarina, Z., Fauziah, I. \& Nazirah, H. (2020). Hubungan Antara Penerimaan, Kesediaan, Logistik Dan Insentif Dengan Penglibatan Program Pendidikan Pencegahan Dadah Dalam Kalangan Keluarga B40. Jurnal Psikologi Malaysia, 34(2), 184-194.

Fadzli, A., \& Sabir, A. G. (2011). Zikir sebagai Modaliti Alternatif Rawatan Pemulihan dadah di Malaysia. Seminar Islam Nusantara Peringkat Asean 2011. Anjuran Kertas Kerja dalam: Pusat Islam Universiti Utara Malaysia di Langkawi.

Fatimah, I. (2008). Solat: Kebaikan dari perspektif Islam. Kuala Lumpur: Universiti Malaya.

Fauziah, I. (2008). Pengaruh Faktor Individu, Persekitaran Sosial Dan Keberkesanan Program Pemulihan Dadah Dalam Kalangan Penagihan Relaps. Tesis PhD, Universiti Putra Malaysia, Serdang

Fauziah, I. Bahaman A. S, Mansor A. T. \& Mohamad Shatar, S. (2009). Faktor Menyumbang Kepada Penagihan Relaps dalam Kalangan Penagih Dadah PUSPEN di Semenanjung Malaysia. Jurnal Agensi AntiDadah Kebangsaan, 5, 235-251.

Fauziah, I., Ezarina, Z., Salina, N., Norulhuda, S. \& Nor Jana, S. (2013). Pengguna Dadah Wanita di Malaysia: Pengalaman Penagihan dan Hubungan Kekeluargaan. Jurnal Teknologi: Social Sciences, 67(1), 17-25.

Fauziah, I., Ezarina, Z., Nor Jana, S., Salina, N. \& Mohd Norahim, M. S. (2017). Faktor-Faktor Penyumbang Ketahanan Diri Penagih Untuk Pulih Bebas Dadah. Journal of Social Sciences and Humanities, 12(1), 60-74.

Galanter, M., Dermatis, H., Bunt, G., Williams, C., Trujillo, M \& Steinke, P. (2006). Assessement of spirituality and its relevance to addiction treatment. Journal of Substance Abuse Treatment, 33, 257-264.

Longshore, D., Anglin, M.D. \& Conner, B.T. (2009). Are religiousity and spiritual useful construct in drug treatment research? Journal of Behavioral Health Services and Research, 36(2): 177 - 188. 
Mahmood Nazar, M. (2006). Penyalahgunaan Dadah Aspek Undang-undang, Pemulihan, Rawatan \& Pencegahan. Selangor: Edusystem Sdn.Bhd.

Mansor, A. T., Mohd Roslan, R., Farhana, S. \& Maziatul Akmal, K. (2017). Penilaian modul pemulihan penagih dadah melalui pendekatan modul ISRA: Satu pendekatan analisis naratif. Jurnal AntiDadah Malaysia, 2017, 1-19

Mohd Alif, J., Siti Hajar, A. B., Jal Abadi, M. Y. Khaitiyah, M. S., Noralina, O. \& Zaiton, A. (2018). Kekurangan Akses kepada Jagaan Lanjutan dan Faktor-Faktor Risiko Yang Membawa Kepada Relaps Dadah dalam Kalangan Bekas Banduan. Jurnal Perspektif, 10(2), 34-44.

Mohd Hefzan, A. \& Muhammad Nubli, A. R. (2019). Pembangunan Model Rawatan Psikospiritual Untuk Meningkatkan Ciri Kepulihan Orang Kena Pengawasan: Satu Tinjauan Literatur. International Journal of Humanities Technology and Civilization, 5(1), 74-88.

Mohamad Johdi, S. (2012). Permasalahan Penagihan Dadah: Tinjauan di Pusat Serenti Selangor. International Seminar on Community Development - SAPKO 2012. Pada 7 - 9 April 2012. Hotel Primer Kuala, University Malaysia of Terengganu. Terengganu.

Nazira, S., Mohammad Rahim, K., Wan Shahrazad, W. S. \& Rozainee, K. (2019). Psikologi Penagihan Dadah: Satu Tinjauan Literatur. Jurnal Psikologi Malaysia, 33(1), 12-33.

Newman, M., Thompson, C. \& Roberts, A. P. (2006). Helping practitioners understand the contribution of qualitative research to evidence-based practice. Evidence-Based Nursing, 9(1), 4-7.

Nurfatin Azfa, M. M., Nobaya, A. \& Hanina Halimatusaadiah, H. (2016). Program Rawatan dan Pemulihan Dadah di Pusat Pemulihan Penagihan Dadah, Kuala Lumpur. Malaysian Journal of Social Sciences and Humanities, 1(3), 14-30.

Peper, E., Tylova, H., Gibney, K.H., Harvey, R., dan Combatalade, D. (2008). Biofeedback Mastery-An Experiential Teaching and Self-Training Manual. CO: AAPB.

Pott, R., Vella, K., Dale, A. \& Sipe, N. (2016). Exploring the usefulness of structural functional approaches to analyse governance of planning systems. Planning Theory, 15(2),162- 189.

Rozmi, I., Nor Azri, A., Fauziah, I. \& Salina, N. (2017). Pengaruh Faktor Individu, Keluarga dan Persekitaran Sosial Terhadap Tingkah Laku Penyalahgunaan Bahan dalam Kalangan Remaja. Akademika, 87(1), 7-16.

Sabir, A. H. \& Fadzli, A., (2014). Pemulihan Dadah Menurut Persepktif Agama di Malaysia. Jurnal Hadhari: An International Journal, 6(1), 75-85.

Said, H. (1999). Tarbiyatuna al-Ruhiyyah. Dalam Yuseri, A., Sapora, S. \& Marina Munira, A.M. (2007). Peranan kerohanian dalam menangani gejala dadah. Jurnal Antidadah Malaysia, Jilid 2(2): 137 154

Simona, M. (2010). Polygraph-Lie Ditector, The Biofeedback, diambil daripada www.fizioms.ro/edu/lp/data/POLIGRAPH.pdf (13 Oktober 2013).

Suppiah, N., Sandra, P. P., Fatimah, M. Z. \& Harikrishnan, A. (2014). Penyalahgunaan Dadah Dan Langkah Mengatasi Dari Segi Kognisi Di Pusat Pengasih Malaysia. Jurnal Peradaban Melayu, 9, 176- 186.

Wan Salmi, W. R. (2012). Pengaruh Psikososial Dan Tahap Pengetahuan Bahaya Dadah Terhadap Penagihan Semula Dalam Kalangan Banduan Penagih Dadah Penjara Malaysia. Tesis Master. Universiti Utara Malaysia. Kuala Lumpur

Unit Perancang Ekonomi, (2020). Indeks Kesejahteraan Hidup Malaysia (IKHM). Putrajaya: Jabatan Perdana Menteri Malaysia.

Willig, C. (2013). Introducing Qualitative Research in Psychology (3 Edition). United Kingdom: Open University Press.

Yuseri, A., Sapora, S. \& Marina Munira, A.M. (2007). Peranan kerohanian dalam menangani gejala dadah. Jurnal Antidadah Malaysia, 2(2), 137-154. 